\title{
DOCUMENTS OF THE KOMI REPUBLIC NATIONAL ARCHIVE ON THE SOLUTION OF THE PROBLEM OF CHILDREN'S HOMELESSNESS AND NEGLECT IN THE SECOND HALF OF THE 1920s
}

\author{
Vladimir N. Bublichenko \\ Ukhta State Technical University, Ukhta, Republic of Komi, Russian Federation
}

\begin{abstract}
The article characterizes the status of the source base which describe the activities of children homelessness and neglect's eradication in the territory of the Komi Autonomous region in the 1920s. The base is considered in the context of the state policy that was held in regard to unsocial young people in that period.

The article presents the original documents of the National archives of the Komi Republic about the regional Department of Education's work connected with children homelessness and neglect's eradication in the Komi region. The most important documents are the state authorities' ordinances and decrees that contain requirement standards how to treat those adolescents who were deprived of family upbringing. The other part of the archival documents includes a list of the factors that produced abandonment and neglect of children in the Komi region; the number of the category of adolescents is given; the public institutions and their activities of dealing with unsocial young people in the region in the 1920s are also described.

As follows from the analysis of the archival documents, those punitive and pedagogical actions and activities that were held to eradicate street homelessness and neglect in the early 1920s were effectively positive. It should be noted that the achievements in this field of activity are related to close coordination and interaction between the public authorities, trade unions and social organizations and the Young Communist League.

Key words: Komi autonomous region, homelessness, neglect, children's institutions, pedology, labour school.

Citation. Bublichenko V.N. Documents of the Komi Republic national archive on the solution of the problem of children's homelessness and neglect in the second half of the 1920s. Vestnik Volgogradskogo gosudarstvennogo universiteta. Serija 4, Istorija. Regionovedenie. Mezhdunarodnye otnoshenija [Science Journal of Volgograd State University. History. Area Studies. International Relations], 2017, vol. 22, no. 2, pp. 87-97. (in Russian).
\end{abstract}

\section{ДОКУМЕНТЫ НАЦИОНАЛЬНОГО АРХИВА РЕСПУБЛИКИ КОМИ О РЕШЕНИИ ПРОБЛЕМЫ ДЕТСКОЙ БЕСПРИЗОРНОСТИ И БЕЗНАДЗОРНОСТИ ВО ВТОРОЙ ПОЛОВИНЕ 1920-Х ГОДОВ}

\footnotetext{
Владимир Николаевич Бубличенко

Аннотация. В статье дана характеристика состояния источниковой базы, которая относится к мероприятиям по ликвидации беспризорности и безнадзорности на территории Коми автономной области в 1920-е годы. Она рассматривается в контексте государственной политики по отношению к внесоциальной молодежи, проводимой в данный период.

В публикации представлены оригинальные документы из фондов Национального архива Республики Коми, характеризующие состояние работы областного отдела народного образования при ликвидации
} 
беспризорности и безнадзорности в Коми автономии. Наиболее важными из выявленных документов являются нормативные распоряжения государственных органов власти, содержащие требования к работе с подростками, лишенными семейного воспитания. В другой части архивных источников содержится перечень факторов, способствующих развитию в Коми области беспризорности и безнадзорности, приводится численность данной категории подростков, дана характеристика работы государственных учреждений, обеспечивающих проведение мероприятий по работе с внесоциальной молодежью на территории области в 1920-е годы.

Как следует из анализа архивных источников, проведенные в первой половине 1920-х гг. мероприятия с целью ликвидации уличной беспризорности и безнадзорности карательного и педагогического характера к концу десятилетия принесли положительный эффект. В документах отмечается, что достигнутый результат в данном направлении связан со слаженным взаимодействием органов государственной власти, профсоюзных и общественных организаций, комсомола.

Ключевые слова: Коми автономная область, беспризорность, безнадзорность, детские учреждения, педология, трудовая школа.

Цитирование. Бубличенко, В. Н. Документы национального архива Республики Коми о решении проблемы детской беспризорности и безнадзорности во второй половине 1920-х годов / В. Н. Бубличенко // Вестник Волгоградского государственного университета. Серия 4, История. Регионоведение. Международные отношения. - 2017. - Т. 22, № 2. - С. 87-97.

Развитие советского общества во многом зависело от создания условий для ликвидации детской беспризорности и безнадзорности. Приоритетные направления государственной политики в решении данной проблемы были сформулированы в первые годы советской власти. Предусматривался комплексный подход с участием ряда учреждений: Государственного совета защиты детей (председатель А.В. Луначарский), комиссии по улучшению жизни детей под руководством Ф.Э. Дзержинского (Деткомиссия при ВЦИК), Наркомата просвещения, Наркомата продовольствия, Наркомата здравоохранения, социальных инспекций на местах, «Фонда им. В.И. Ленина для оказания помощи беспризорным детям» и другие учреждения.

Первоочередными мерами становилось изъятие беспризорных подростков с улицы и размещение их в государственные учреждения, обеспечение питанием, одеждой, жильем, медицинской помощью, проведение других мероприятий по защите несовершеннолетних. Предпочтение отдавалось мерам воспитательного характера. В случаях, когда они не могли привести к исправлению несовершеннолетнего правонарушителя, принималось решение о вынесении судебного решения.

«Общественно-опасные» подростки в возрасте от 17 до 21 года помещались в реформатории. Они создавались органами юстиции совместно с Наркоматом просвещения
[5, с. 28]. В учреждениях велось обучение, воспитание и подготовка к трудовой жизни той части советской молодежи, которая жила вне семьи, находилась под влиянием взрослых преступников и нуждалась в более эффективных методах перевоспитания. Исследователи отмечают, что реформатории стали важной частью в подготовке дальнейшей организации детских исправительно-трудовых учреждений, но ввиду экономических трудностей, отсутствия необходимых педагогических кадров не получили широкого распространения [1;7].

Советская нормативно-правовая база 1920-х гг. предусматривала перевоспитание несовершеннолетних правонарушителей через закрытые учреждения интернатского типа со строгим педагогическим режимом (по классификации ИТК РСФСР 1924 г. - трудовые дома). В них создавались условия для повышения образовательного уровня подростков, организации их профессионального обучения с целью формирования «самодеятельных и сознающих свои права и обязанности граждан» [4, с. 49].

Для наиболее педагогически запущенных подростков была открыта сеть учреждений воспитательно-карательного типа - трудовые коммуны производственной или сельскохозяйственной направленности. Наиболее известными были две из них - Первая Болшевская трудкоммуна ОГПУ (создана в 1924 г., заведующий Ф.Г. Мелихов) и Харьковская (созда- 
на в 1927 г., руководитель А.С. Макаренко) $[2$, c. $58-61]$.

Привлечение беспризорных и безнадзорных подростков к ответственности за преступления являлось составной частью воздействия на них с целью локализации и предотвращения развития рецидива. Тем не менее приоритет отдавался размещению несовершеннолетних, которые потеряли связь с родителями, в детдома, поскольку в 1920-е гг. возвращение их в семьи было затруднено. Развитие получила практика передачи детдомовцев на воспитание в крестьянские семьи с обеспечением их льготами по налогообложению [8, л. 293].

К решению проблемы детской беспризорности в 1920-е гг. привлекались работники общественных и профсоюзных организаций, комсомол. Обобщался и пропагандировался передовой опыт, разрабатывались методики по работе с подростками, потерявшими связь с семьей. В результате проведенных мероприятий к концу 1920-х гг. численность беспризорных и безнадзорных подростков в стране снизилась с 45000 человек в 1928-1929 гг. до 10000 в 1930-1931 годах [3, с. 5].

Документальные источники по истории ликвидации беспризорности и безнадзорности несовершеннолетних в 1920-е гг. появились во время реализации государственной политики в данном направлении. К наиболее важным из них относятся нормативные материалы, опубликованные в сборниках «Собрание узаконений и распоряжений Рабочего и Крестьянского правительства» официального государственного органа, издававшегося с декабря 1917 года. В отдельных случаях тексты документов редактировались составителями и отличаются от архивных оригиналов.

Другая часть источников связана с публикацией теоретических статей и выступлений руководителей советского государства, непосредственно занимавшихся проблемами беспризорности и безнадзорности несовершеннолетних. Среди такого рода источников выделяются работы В.И. Ленина, Ф.Э. Дзержинского, А.В. Луначарского, Н.К. Крупской. В концептуальном аспекте лейтмотив публикаций сводился к обоснованию нескольких принципиально важных тезисов. Во-первых, детская беспризорность тяжело отражалась на личности подростка, создавая угрозу для его нормального развития. Во-вторых, факт наличия в советском государстве несовершеннолетних, лишенных семейного воспитания, создавал угрозу для его успешного развития. В-третьих, признавая, что детская беспризорность являлась трагедией подрастающего поколения, советские руководители опасались роста преступности среди «антиобщественных, антисоциальных» подростков, выдвигая задачу ликвидации данных явлений. В советской историографии статьи партийных и государственных деятелей 1920-х гг. о борьбе с беспризорностью несовершеннолетних стали основной источниковой базой для исследователей.

На протяжении 1920-х гг. в советской педагогике шла апробация новых методик по работе с подростками, в том числе из числа беспризорных и безнадзорных. Отдельные идеи педагогов-новаторов носили дискуссионный характер. К числу таких теорий относилась педология - наука о возможности развития «нового человека» в условиях социалистического общества, которая «находилась на стыке между общественными и естественными дисциплинами» [6, с. 5]. Теоретическое развитие она получила в работах А.Б. Залкинда и на протяжении 1920 -х гг. применялась в практической деятельности детских городков для беспризорных, в том числе расположенных на территории Коми автономии [8, л. 242]. Составной частью педологической теории, применяемой в работе с беспризорными подростками, стало учение Л.С. Выготского о единой трудовой школе. Характерным примером обобщения опыта руководства детскими специальными учебными заведениями являются работы А.С. Макаренко, которые изучались и использовались в практической деятельности детских закрытых учреждений НКВД - МВД СССР на протяжении всего периода их функционирования. Несмотря на имеющиеся недостатки, разработки советских педагогов-новаторов стали важной составной частью опубликованных источников по истории беспризорности 1920-х годов.

В советской историографии публикация новых источников по проблеме ограничива- 
лась. Принципиальные изменения произошли в начале 2000-х гг. после выхода в серии «Россия. ХХ век. Документы» сборников: «ГУЛАГ: Главное управление лагерей. 1918-1960» и «Дети ГУЛАГа. 1918-1956» [5; 6]. В них содержались основополагающие декреты, постановления, инструкции и циркуляры по вопросам работы с беспризорными и безнадзорными несовершеннолетними в 1920-е годы. Отдельный комплекс источников, представленных в публикациях, составили письма советских граждан государственным и общественным деятелям по вопросам улучшения положения подростков, лишенных семейного воспитания, бедственном положении детей и отношении к ним органов власти. В результате издания указанных материалов была устранена тенденция переиздания официально-охранительных источников, что привело к расширению проблематики научных исследований. Но основной корпус документов по истории беспризорности и безнадзорности в СССР до сих пор не введен в научный оборот. Часть из него находится в фондохранилищах региональных архивов, представляя важный источниковедческий материал.

Несмотря на то что на территории Коми автономной области численность беспризорных и безнадзорных несовершеннолетних в 1920-е гг. была небольшой, местными органами власти принимались комплексные меры с целью ликвидации негативных явлений. Для этого выделялись средства, открывались специальные учреждения, велась подготовка педагогических кадров, поддерживалась связь с местным населением.

В фонде «Отдела народного образования при Коми облисполкоме» Национального архива Республики Коми (ф. Р-148, оп. 1, 1274 ед. хр.) отложился ряд документов, которые характеризуют различные аспекты при ликвидации беспризорности и безнадзорности на территории автономии в 1920-е годы. Они представлены как в рукописном, так и в печатном виде. На некоторых из них имеются пометки чаще всего делопроизводственного характера.

Среди материалов республиканского архива важное место занимают циркуляры и распоряжения высших органов советской власти по улучшению жизни детей и социально-пра- вовой охране несовершеннолетних. Как пример такого вида источников в статье публикуются извлечения из циркуляра ВЦИК СССР от 17 января 1927 года. Он отражает требования к организации распределения выпускников детдомов и ставит перспективные задачи по ликвидации выявленных недостатков (документ № 1). В фондах республиканского архива сохранилась его заверенная машинописная копия. На первой странице документа в левом верхнем углу сделана надпись чернильной ручкой: «Елькину. Для свед. 18/II.27». Распоряжение относилось к инспектору Соцвоса Коми автономной области, в компетенцию которого входила организация социальноправовой охраны детей.

В завершении подборки документов приведен фрагмент из директивного письма Деткомиссии ВЦИК за 1929 г. (документ № 4). Точную дату появления документа установить невозможно ввиду отсутствия соответствующих данных. Республиканский архив располагает типографским экземпляром письма. Из содержания документа видно, что в нем подводятся итоги работы государственных и общественных организаций по ликвидации беспризорности и безнадзорности несовершеннолетних за несколько последних лет в целом по стране. Особое внимание в письме уделено необходимости координации действий всех участников, задействованных в данном процессе, и созданию условий дальнейшей адаптации в обществе бывших беспризорных.

К числу приоритетных направлений в работе Коми областного отдела образования на протяжении 1920-х гг. относилось создание условий по предотвращению роста уличной беспризорности путем передачи подростков, потерявших связь с семьей, в крестьянские семьи для воспитания. Для этого составлялся пакет документов: акты обследования подростка-сироты или детдомовца и семьи, изъявившей желание принять на воспитание такого ребенка, опись имущества несовершеннолетнего. Такая группа источников, отложившихся в архиве Республики Коми, характеризует профилактическое направление работы государственных организаций автономной области, занимавшихся социально-правовыми вопросами охраны детей. 
С целью обеспечения системного подхода при ликвидации детской беспризорности в Коми автономии был составлен перспективный план на 1927-1930 гг. (документ № 2). В нем отражены сведения о причинах беспризорности, численный и возрастной состав данной группы подростков, дан анализ состояния существующей сети учреждений для размещения потерявших связь с семьей несовершеннолетних и возможные пути ее расширения, намечен план профилактических мероприятий и возможные источники их финансирования.

Одним из ведущих воспитательно-образовательных учреждений для беспризорных в Коми автономии был Кылтовский детгородок, организованный в 1923 г. после реорганизации Крестовоздвиженского женского монастыря. Учреждение было закрыто в 1930 г. после преобразования в Сельхозлаг. Фонды архива Республики Коми располагают комплексом документов по истории Кылтовского детгородка. Среди них протоколы заседаний совета педагогов, акты и заключения по результатам обследования учреждения. В протоколе заседания секции Соцвоса Коми области от 18 сентября 1928 г. зафиксирован доклад студента о работе Кылтовского детгородка для беспризорных (документ № 3). Информационная важность данного источника связана с возможностью подтвердить тезис о том, что в педагогической работе с беспризорными подростками в 1920 -е гг. широко применялись методические разработки А.Б. Залкинда, Л.С. Выготского, А.С. Макаренко и других педагогов-новаторов. Они были известны на периферии Советского Союза, к которой относилась Коми автономия.

Публикуемые ниже документы расположены в хронологической последовательности с сохранением орфографии и стилистической особенности оригиналов. Они снабжены заголовками, которые характеризуют видовую разновидность документа, его содержание, адресата. Документы приведены в извлечении, что оговаривается в заголовке предлогом «из». Текст источника завершается архивной легендой, содержащей номера фонда, описи, единицы хранения, листа в деле.

Отложившиеся в фондах Национального архива Республики Коми письменные ис- точники характеризуют взаимодействие органов народного образования и социально-правовых учреждений, которые в пределах своей компетенции работали над решением проблемы беспризорности на территории Коми области в 1920 -е годы.

\section{Документ № 1}

\section{Из циркуляра Председателя ВЦИК}

\section{Центральным исполнительным комитетам автономных республик, краев, областей и губернским исполнительным комитетам}

17 января 1927 г. Копия Москва, Кремль Циркулярно

В целях урегулирования дела борьбы с детской беспризорностью и, в частности, в целях обеспечения правильного бесперебойного выпуска из детских домов подростков, достигших рабочего возраста, на производство и облегчения выпуска части детей путем передачи их на воспитание в крестьянские семьи, Президиумом Всероссийского Центрального Исполнительного Комитета и Советом Народных Комиссаров РСФСР был издан в истекшем году ряд постановлений.

При этом основная идея, руководившая правительством, состояла и состоит в том, чтобы всемерно добиваться увеличения пропускной способности детских домов, с целью охвата последними новых кадров беспризорных детей улицы, путем приема их на места, выпускаемых из детских домов.

Однако практика мест в борьбе с детской беспризорностью за последний год вызывает ряд сомнений и порождает тревогу за результаты проводимой работы в этой области, причем основанием для такого рода сомнений служит следующее:

1. Перечисленные выше законодательные акты, открывшие значительные возможности организованного выпуска из детских домов воспитанников, проводятся в жизнь достаточно интенсивно. Возможности выпуска были использованы, в первую очередь, в целях сокращения сети детских учреждений и контингента детей в них, а тем самым и расходов по их содержанию. 


\section{ОТЕЧЕСТВЕННАЯ ИСТОРИЯ}

2. Некоторые исполнительные комитеты ограничивают круг работы по борьбе с беспризорностью обслуживанием исключительно детей - уроженцев своей губернии, области или округа. Принимая во внимание, что большинство таких беспризорных детей (особенно так называемые дети-бродяжки) сплошь и рядом отрываются от места своего рождения, в связи с чем и беспризорность должна рассматриваться, как явление экстерриториальное, такое направление работы со стороны органов, ведущих борьбу с беспризорностью, должно быть признанным ненормальным.

Ввиду изложенного и признавая необходимым привести дело борьбы с детской беспризорностью в соответствии с общим государственным и хозяйственным строительством страны, Президиум Всероссийского Центрального Исполнительного Комитета и Совет Народных Комиссаров РСФСР обращают внимание местных исполнительных комитетов на необходимость усилить борьбу с детской беспризорностью и, в частности, принять следующие меры:

1) Не ослабляя работы по организованному выпуску из детских учреждений воспитанников в установленном законом порядке, обратить особое внимание на дальнейший охват этими учреждениями беспризорных детей улицы, ни в коем случае не допуская свертывания сети, впредь до рассмотрения и согласования общего для РСФСР ориентировочного плана по борьбе с беспризорностью.

2) Обслуживание беспризорных детей отнюдь не должно ограничиваться только детьми-уроженцами данного исполнительного комитета, а должно быть распространено на всех без исключения беспризорных детей, независимо от места их рождения.

3) Выпускаемые из детских домов на производство должны быть обеспечены жилой площадью, для чего, если потребуется, необходимо предоставить последним льготы, установленные для демобилизованных красноармейцев.

Председатель Всероссийского Центрального Исполнительного Комитета $\mathrm{M}$. Kaлинин.

ГУ «НАРК». Ф. Р-148. Оп. 1. Д. 351. Лл. 484-486. Машинописная копия.

\section{Документ № 2}

\section{Из перспективного плана ликвидации детской беспризорности по области}

Коми в течение трехлетья (1927-28 1929-30 бюджетные года)

I. Установление принципов в определении характера и степени беспризорности и, в связи с этим, определение количества беспризорных детей по области.

На основании постановления ВЦИК и СНК РСФСР от 8 марта 1926 г. государством принимаются меры охраны в отношении беспризорных, не достигших 16 лет и находящихся в условиях опасных для их физического или общественно-трудового развития.

В соответствии с характером и степенью беспризорности устанавливаются две категории беспризорных детей:

a) нуждающиеся в полном обеспечении и воспитании, к каковым отнести:

1) круглые сироты, а также не имеющие братьев и сестер, которые были бы обязаны и могли бы принять на себя заботу о них;

2) потерявших связь с родителями и родственниками;

3) изъятых постановлением суда или комиссий по делам несовершеннолетних из семьи вследствие преступлений или порочной жизни их родителей или лиц, у которых они воспитывались, или вследствие злоупотреблений в отношении их родительскими правами;

4) детей подкинутых;

б) нуждающиеся в охране и в мерах временной или частичной помощи и воспитании. К таковым отнести:

1) оказавшихся беспризорными вследствие тяжелой болезни или инвалидности, полной нетрудоспособности родителей или лиц, у которых они воспитывались, в тех случаях, когда находящиеся на попечении одной только матери, лишенной всякого заработка и не получающей материальной поддержки от мужа, родственников и др. лиц;

2) оказавшихся беспризорными вследствие временного отсутствия родителей или лиц, на содержании которых они находились или воспитывались как те: лишение их свободы, нахождение в больнице на лечении и т. д. 
В связи с установленными принципами, на основе имеющихся из мест материалов и результатов проверки определяется нижеследующее количество беспризорных по области:

1. Нуждающихся в полном обеспечении и воспитании:

Устьвымский уезд

Ижемский »

97 чел.

Сысольский »

$70 »$

Устькуломский »

$68 \gg$

$65 »$

ВСЕГО: 300 детей

2. Нуждающихся в мерах временной или частичной помощи и воспитании:

Устьвымский уезд

Устькуломский »

152 чел.

Ижемский »

$130 »$

Сысольский »

$100 »$

$68 »$

ВСЕГО: 450 детей

Основными предпосылками, вызвавшими в столь значительных размерах детскую беспризорность по области, без сомнения, являются годы войны и хозяйственной разрухи. В текущие годы общего восстановления народного хозяйства, материально-экономическое положение населения области из года в год постоянно улучшается, но все же, местами материальная нужда деревенской бедноты до сих пор не изжита, и этот слой населения продолжает питать детскую беспризорность новыми кадрами.

Другими причинами, порождающими детскую беспризорность, не в меньшей степени, чем указанная выше, является: а) распад семьи; б) выпад детей из семьи в результате неумелого подхода родителей к своим детям, а иногда и жестокого обращения с ними; в) беспризорность, имеющая обычно место в семьях, хотя и лишенных отца, не имеющих возможности, а иногда и уменья со стороны матери уделять должное внимание воспитанию своих детей.

Нужно еще указать на имеющий место в наших условиях рецидив беспризорности. Этот рецидив дает Кылтовский детгородок в виде бегства воспитанников (за последние полгода сбежало 12 человек).

II. Состояние существующей сети и число мест, могущих быть использованными.

В течение ряда последних лет контингент детей существующих детдомов ввиду недостатка жилой площади в последних сни- жен на 75 человек. В настоящее время имеющимися детдомами охватывается следующее количество беспризорных: а) Кылтовским детгородком - 200 человек, б) Устьсысольским детприемником - 15 человек и в) Мохчанским (Ижма) детдомом 30 человек. Всего 245 человек.

Детгородок при нормальной постановке в нем работы и при известном дооборудовании имеет все необходимые условия для подготовки своих воспитанников к общественнополезной трудовой деятельности. Там имеется: большое сельское хозяйство, ряд мастерских, нормальная школа четырехлетка и детский сад.

Остальные детдома данных условий до сих пор не имели и являлись лишь как бы общежитиями для беспризорных детей. Только с начала настоящего бюджетного года в о3наченных детдомах преступлено к организации производственной базы (в детприемнике чулочно-швейной мастерской, в Мохчанском детдоме - столярной мастерской).

За истекший указанный год удалось пропустить из детдомов:

1) в школы повышенного типа Соцвоса и профобра до 30 чел.

2) в частный патронат $12 »$,

3) в учреждения и предприятия $10 »$.

Всего до 52 человек, однако, часть из переданных воспитанников школы повышенного типа (до 10 человек) продолжают числиться в списках детдомов и получать оттуда необходимую материальную помощь. Таким образом, фактически выпуск за год выразился числом в 42 чел. (17\%), взамен которых в таком же количестве охвачены новые беспризорные. Средним процентом выпускаемых воспитанников от общего числа детей детдомов можно установить примерно $12 \%$.

V. Профилактические мероприятия.

В качестве профилактических мероприятий необходимо провести в жизнь следующее:

а) меры по созданию условий для нормального физического развития детей, к каковым нужно отнести:

1) оказание материальной помощи на дому и в школе. В данном отношении до настоящего времени помощью на дому, главным образом, обслуживались нуждающиеся дети ближайших 
к городу районов. В дальнейшем необходимо охватить помощью на дому материально необеспеченных детей на периферии.

Помощь нуждающимся детям в школе должна выражаться в снабжении их бесплатно необходимыми учебными пособиями, организацией питания, в удовлетворении необходимой одеждой, обувью.

3) Своевременное проявление заботы на местах к учреждению опеки в одних случаях и к передаче в патронат - других. Указанные формы предотвращения беспризорности в условиях деревни являются весьма существенными и на применение их в более широких размерах нужно обратить самое серьезное внимание. детей

б) Меры социально-правовой охраны

В данном случае нужно принять меры к организации на местах детской юридической консультации по вопросам, связанным с охраной и защитой личных и имущественных прав несовершеннолетних (взыскание алиментов, исходатайствование в нужных случаях пенсии, защита от злоупотреблений своими правами родителей и т. д.).

в) Меры по организации социально-культурной помощи детям.

ГУ «НАРК». Ф. Р-148. Д. 431. Лл. 172, 173, 175, 176. Подлинник. Машинопись.

\section{Документ № 3}

\section{Из протокола заседания секции Соцвоса от 18 сентября 1928 г.}

I. СЛУШАЛИ: Краткий доклад студента-практиканта при городке тов. Латкина о состоянии и работе Кылтовского городка.

ПОСТАНОВИЛИ: 1) Обучение беспризорных детей на основе труда и подготовка их через производство (сельскохозяйственное и труд в мастерских) к трудовой деятельности в условиях Кылтовского городка является основной задачей. Секция считает, чтобы труд детей школьного возраста рассматривался именно как труд политехнический. Для учащихся переростков (старше 12 лет), естественно, обучение трудовым процессам носит уже специальный (профессиональный) характер.
2) Правильно налаженная самоорганизация детской массы городка является основным условием, дающим возможности к нормальной постановке всей учебно-воспитательной и хозяйственной работы в городке. В связи с этим предприняты шаги в направлении большой активизации детей в области самоуправления и самоорганизации при надлежащей постановке дела должны дать положительные результаты. Однако, детская масса, не подавляясь авторитетом руководителей и не находясь у них на поводу, все-таки со стороны последних должна встречать надлежащее руководство.

3) Считая организацию возрастных групп для вечерних занятий под руководством педагогов-воспитателей целесообразной, в то же время секция возражает против составления производственных групп исключительно под руководством и влиянием старших воспитанников. Производственная работа в условиях городка имеет исключительное значение, и оставить выполнение данной работы безо всякого педагогического руководства нельзя.

4) Следующими очередными задачами на основе доклада секция считает:

a) необходимость организации работ по педалого-педагогическому изучению детей городка и создание для этого необходимых условий;

б) проведение общего медико-педологического обследования детей силами уездных или областных медработников;

в) решительную борьбу с антисанитарными условиями городка;

г) усиление воспитательной работы с детьми и подростками;

д) привитие воспитанникам чувства коллективизма и товарищеской солидарности друг к другу;

е) изжитие мелкособственнических тенденций у детей и приучение дорожить казенными вещами;

ж) организацию самообразовательной работы среди руководителей-педагогов городка через использование заочных курсов Института повышения квалификации педагогов при Главсоцвосе.

ГУ «НАРК». Ф. Р-148. Оп. 1. Д. 431. Лл. 242, 242 об. Подлинник. Машинопись. 
Документ № 4

\section{Из письма Деткомиссии при ВЦИК}

\section{ко всем общественным организациям, участвующим в деле борьбы с детской беспризорностью и безнадзорностью}

19292.

Уважаемые товарищи!

Размер массовой уличной беспризорности значительно сократился. Уличная детская беспризорность в настоящее время исчисляется уже не сотнями и не десятками тысяч, как это было несколько лет тому назад.

Отмечая это громадное достижение, необходимо, однако, подчеркнуть, что уличная детская беспризорность в целом еще не изжита, что имеется еще ряд причин, порождающих новую беспризорность, в связи с чем в дальнейшей работе по борьбе с детской беспризорностью должны быть выдвинуты следующие три основные задачи.

1. Доведение до конца ликвидации уличной беспризорности и установление такого порядка и таких мероприятий, которые обеспечивали бы недопущение накапливания на улицах беспризорных в дальнейшем.

2. Перевоспитание подобранных с улиц и находящихся в настоящее время в детских учреждениях беспризорных и устройство их в общественно-полезную трудовую жизнь.

3. Борьба с детской безнадзорностью.

Для удовлетворительного разрешения первой задачи необходимо углубить плановую работу на улице, обеспечив постоянный подбор появляющихся на улицах беспризорных детей и устройство их или путем помещения в соответствующие детские учреждения, или путем возвращения в семьи, направления на работу и т. д.

После проведения кампаний по массовому изъятию с улиц беспризорных необходимо, чтобы наблюдение за улицей, углубленно-плановая работа на ней была бы постоянной неотъемлемой частью работы всех подлежащих государственных учреждений и чтобы эта работа находилась в должной мере под наблюдением и контролем нашей общественности.

Вторая задача - задача перевоспитания и устройства в самостоятельную жизнь нахо- дящихся в детучреждениях беспризорных в целом упирается в состояние и работу этих детских домов.

Детские дома в значительной своей части до сих пор испытывают нужду в обмундировании, оборудовании, питании и т. д. Зачастую, даже при наличии материальных возможностей, состояние детдомов, хозяйствование в них, работа с детьми не только неудовлетворительны, но из рук вон плохи.

Всё это выдвигает срочную необходимость, чтобы, помимо усиления работы по улучшению работы д/домов со стороны местных исполнительных комитетов и соответствующих органов, общественных организаций, в первую очередь Общества «Друг детей», усилили бы свое внимание д/домам, в частности расширили бы и укрепили бы общественное шефство над д/учреждениями. При этом это шефство должно быть организовано таким образом, чтобы охватить абсолютно все детские учреждения и, во-вторых, чтобы это шефство не рассматривалось бы только, как мера материальной помощи, но как общественный контроль, общественное наблюдение за детдомами, за жизнью и бытом живущих в них детей.

Далее, говоря о положении и о работе д/домов, необходимо коснуться вопроса о выпуске и о надлежащем устройстве воспитанников д/домов в трудовую жизнь.

В настоящее время этот выпуск стал более организованным, плановым и дающим большой эффект и осуществляется он по следующим направлениям: устройство на фабрики и заводы, в коллективные хозяйства и совхозы, в ВУЗы, в крестьянские семьи, к кустарям и ремесленникам, а также и к родным. Эти пути устройства бывших воспитанников детдомов в значительной мере оправдали себя, но и здесь есть ряд недочетов, на которые также в дальнейшем следует обратить самое серьезное внимание.

Обращая внимание общественности на изложенные недочеты в области борьбы с детской беспризорностью и безнадзорностью и на необходимость их скорейшего изжития, Деткомиссия при ВЦИК считает своей обязанностью особо широко и особо резко выдвинуть третью задачу, а именно вопрос борьбы с детской безнадзорностью. Работа по 
обслуживанию этого кадра детей, в настоящее время уже осуществляется рядом государственных учреждений, а также общественных организаций. Но, безусловно, как объем этой работы, так и темп ее осуществления далеко еще недостаточны. Государство материально не в состоянии взять на себя разрешение целиком всей этой задачи. Только при самом активном участии в этой работе общественных организаций, только при самом широком привлечении к участию в ней самого населения, возможно добиться должных и нужных результатов в этой области.

Обращая внимание общественных организаций на указанные задачи в области борьбы с детской беспризорностью и безнадзорностью, Деткомиссия при ВЦИК считает необходимым кроме того и одновременно с этим отметить также работу по охране материнства и младенчества и работу по охране здоровья детей. В свою работу по охране детства общественные организации должны включить и эти два раздела.

Кроме того, нельзя обойти молчанием одного также очень большого и остро стоящего в настоящее время вопроса, а именно - вопроса о трудовой помощи беспризорным подросткам свыше 16 лет. Этот вопрос в полной и нужной мере до сих пор не урегулирован. Это дело осуществляется рядом учреждений и организаций, но общего плана и согласованности в действиях между ними нет.

Деткомиссия при ВЦИК считает необходимым обратить особое внимание общественных организаций на контроль, на наблюдение за правильностью, целесообразностью и экономностью расходования соответствующими органами отпускаемых им на мероприятия по борьбе с детской беспризорностью и безнадзорностью средств.

Хотя размер отпускаемых государством и Деткомиссией при ВЦИК средств на борьбу с детской беспризорностью еще недостаточен для удовлетворения всей нужды в этой области, но по своей абсолютной величине этот расход очень значителен и измеряется десятками миллионов рублей. Поэтому вопрос о том, как используются эти средства, есть вопрос чрезвычайно большой и требующий общественного контроля. Необходимо, чтобы РКИ и Госфинконтроль также усилили бы свое внимание к этому делу.

И. о. Председателя Деткомиссии при ВЦИК Кутузов.

ГУ «НАРК». Ф. Р-148. Оп. 1. Д. 431. Лл. 112-112 об., 113. Типографский экз.

\section{СПИСОК ЛИТЕРАТУРЫ}

1. Астемиров, 3. А. Из истории развития учреждений для несовершеннолетних правонарушителей / 3. А. Астемиров // Предупреждение преступности несовершеннолетних : сб. ст. - М. : Юрид. лит., 1965. - С. 253-269.

2. Белова, Н. А. Из опыта деятельности трудовых коммун по перевоспитанию несовершеннолетних правонарушителей / Н. А. Белова // Проблемы формирования ювенальной юстиции в России и создания исправительных учреждений нового типа для несовершеннолетних : сб. материалов Междунар. науч.-практ. семинара. - Вологда : ВИПЭ ФСИН России, 2011. - С. 58-61.

3. Бубличенко, В. Н. Создание и развитие детских закрытых учреждений НКВД - МВД СССР на Европейском Севере России (1935-1956 гг.) / В. Н. Бубличенко. - Ухта: Изд-во УГТУ, 2010. - 166 с.

4. ГУЛАГ: Главное управление лагерей. 1918 1960 / сост. А. И. Кокурин, Н. В. Петров. - М. : МФД, 2000. $-888 \mathrm{c}$.

5. Дети ГУЛАГа. 1918-1956 / сост. С. С. Виленский, А. Н. Кокурин, Г. В. Атамашкин, И. Ю. Новиченко. - М. : МФД, 2002. - 631 с.

6. Залкинд, А. Д. Педология в СССР / А. Д. Залкинд. - М. : Работник просвещения, 1929. - Электрон. текстовые дан. - Режим доступа: http://elib. gnpbu. ru/ text/zalkind_pedologiya-v-sssr_1929. - Загл. с экрана.

7. Крюкова, Н. И. История развития уголовного законодательства об ответственности несовершеннолетних / Н. И. Крюкова. - Электрон. текстовые дан. - Режим доступа: http://kirov.perm.sudrf.ru. Загл. с экрана.

8. Переписка о беспризорных детях 19281929 гг. // ГУ «Национальный архив Республики Коми» (ГУ «НАРК»). - Ф. Р-148. - Оп. 1. - Д. 431.

\section{REFERENCES}

1. Astemirov Z.A. Iz istorii razvitiya uchrezhdeniy dlya nesovershennoletnikh pravonarushiteley: sb. statey [From the History of Development of Institutions for Juvenile Offenders]. Moscow, Yur. lit. Publ., 1965, pp. 253-269.

2. Belova N.A. Iz opyta deyatelnosti trudovykh kommun po perevospitaniyu nesovershennoletnikh 
В.Н. Бубличенко. Документы национального архива Республики Коми о детской беспризорности

pravonarushiteley [From the Experience of Labour Communes for Rehabilitation of Juvenile Offenders]. Problemy formirovaniya yuvenalnoy yustitsii $v$ Rossii i sozdaniya ispravitelnykh uchrezhdeniy novogo tipa dlya nesovershennoletnikh: sb. materialov mezhdunarodnogo nauchno-prakticheskogo seminara [Problems of the Formation of Juvenile Justice in Russia and the Creation of Correctional Facilities of a New Type for Minors: Collected Materials of the International Scientific and Practical Seminar]. Vologda, VIPE FSIN Rossii, 2011, pp 58-61.

3. Bublichenko V.N. Sozdanie i razvitie detskikh zakrytykh uchrezhdeniy NKVD - MVD SSSR na Evropeyskom Severe Rossii (1935 - 1956 gg.) [Creation and Development of Children's Closed Institutions of NKVD - MIA of the USSR in the European North of Russia (1935-1956)]. Ukhta, UGTU Publ., 2010. 166 p.
4. Kokurin A.I., Petrov N.V. GULAG: Glavnoe upravlenie lagerey. 1918-1960 [Gulag: General Directorate ofCamps. 1918-1960]. Moscow, MFD Publ., 2000. 888 p.

5. Kokurin A.I., Petrov N.V. Deti GULAGa. 19181956 [Children of the Gulag. 1918-1956]. Moscow, MFD Publ., 2000.631 p.

6. Zalkind A. D. Pedologiya v SSSR [Pedology in the USSR]. Moscow, Rabotnik prosveshcheniya Publ., 1929. URL: http://elib.gnpbu.ru/text/ zalkind_pedologiya-v-sssr_1929.

7. Kryukova N.I. Istoriya razvitiya ugolovnogo zakonodatelstva ob otvetstvennosti nesovershennoletnikh [History of Criminal Legislation on Juvenile Justice]. URL: http://kirov.perm.sudrf.ru.

8. Perepiska o besprizornykh detyakh $1928-$ 1929 gg. [Correspondence about Street Children in 1928-1929]. GU «Natsionalnyy arkhiv Respubliki Komi» (GU «NARK»), F. R-148, Op. 1, D. 431.

\section{Information about the Author}

Vladimir N. Bublichenko, Candidate of Sciences (History), Associate Professor, Department of History and Culture, Ukhta State Technical University, Pervomayskaya St., 13, 169300 Ukhta, Republic of Komi, Russian Federation, vbublichenko@mail.ru, http://orcid.org/0000-0003-4262-2644.

\section{Информация об авторе}

Владимир Николаевич Бубличенко, кандидат исторических наук, доцент кафедры истории и культуры, Ухтинский государственный технический университет, ул. Первомайская, 13, 169300 г. Ухта, Республика Коми, Российская Федерация, vbublichenko@mail.ru, http:/orcid.org/ 0000-0003-4262-2644. 